\title{
High temperature ultrasonic sensor for fission gas characterization in MTR harsh environment
}

\author{
O. Gatsa, P. Combette, E. Rozenkrantz, D. Fourmentel, C. Destouches, and J.Y. Ferrandis
}

\begin{abstract}
In the contemporary world, the measurements in hostile environment is one of the predominant necessity for automotive, aerospace, metallurgy and nuclear plant. The measurement of different parameters in experimental reactors is an important point in nuclear power strategy. In the near past, IES (Institut d'Électronique et des Systèmes) on collaboration with CEA (Commissariat à l'Energie Atomique et aux Energies Alternatives) have developed the first ultrasonic sensor for the application of gas quantity determination that has been tested in a Materials Testing Reactor (MTR). Modern requirements state to labor with the materials that possess stability on its parameters around $350{ }^{\circ} \mathrm{C}$ in operation temperature. Previous work on PZT components elaboration by screen printing method established the new basis in thick film fabrication and characterization in our laboratory. Our trials on Bismuth Titanate ceramics showed the difficulties related to high electrical conductivity of fabricated samples that postponed further research on this material. Among piezoceramics, the requirements on finding an alternative solution on ceramics that might be easily polarized and fabricated by screen printing approach were resolved by the fabrication of thick film from Sodium Bismuth Titanate (NBT) piezoelectric powder. This material exhibits high Curie temperature, relatively good piezoelectric and coupling coefficients, and it stands to be a good solution for the anticipated application.
\end{abstract}

In this paper, we present NBT thick film fabrication by screen printing, characterization of piezoelectric, dielectric properties and material parameters studies in dependence of temperature. Relatively high resistivity in the range of $1 \cdot 10^{13} \mathrm{Ohm} \cdot \mathrm{cm}$ for fabricated thick film is explained by Aurivillius structure in which $a$ - and $b$ - layers form perovskite structure between oxides of $c$ - layer. Main results of this study are presented and discussed in terms of feasibility for an application to a new sensor device operating at high temperature level $\left(400^{\circ} \mathrm{C}\right)$. Piezoelectric parameters enhancement and loss reduction at elevated temperatures are envisaged to be optimized. Further sensor development and test in MTR are expected to be realized in the near future.

Index Terms - acoustic measurements, high temperature transducer, nuclear instrumentation, screen printing, sodium bismuth titanate.

This work, presented at the International Conference on Advancements in Nuclear Instrumentation Measurement Methods and their Applications, June 19-23, 2017

O. Gatsa, P. Combette, E. Rosenkrantz, and J. Y. Ferrandis, are with the CNRS-University Montpellier 2, Institute of Electronics and Systems, UMR 5214, F-34095 Montpellier, France (e-mail: oleksandr.gatsa@ies.univmontp2.fr).

D. Fourmentel and C. Destouches are with the Reactor Studies Department, French Nuclear Energy and Alternative Energies Commission, CEA Cadarache, F-13108 Saint Paul-Lez-Durance, France (e-mail: damien.fourmentel@cea.fr).

\section{INTRODUCTION}

$\mathrm{N}$ UCLEAR fuel rods lifetime optimization will increase the combustion rate of nuclear fuel, hence reducing the volume of waste to be recycled. In the case of previous studies, the measurements of fission gas composition in REMORA-3 experiment [1] via in-pile control of fuel rods interior environment have been carried out. The gas mixtures (Helium and fission gases) were successfully monitored during the experiment up to operation temperature of $200^{\circ} \mathrm{C}$. The measurement principle was based on data processing of the registered echograms. REMORA-3 experiment was a first step in the field of gas composition monitoring under harsh environment conditions in a nuclear plant. It opens new possibilities in the field of qualitative measurements by an acoustic approach.

Currently, we work on a new ultrasonic sensor for an experimental material testing reactor Jules Horowitz with a temperature constraint of $400^{\circ} \mathrm{C}$. The difficulties with brazing and ensuring of a parallelism between an active element and stainless steel plate led us to work on another sensor configuration concept which is based on the screen-printing. Manufacturing of the ceramic material by this method ensures high flexibility on sensor fabrication: direct deposition can be performed on different structure types; the deposition area shape of material can be easily chosen.

\section{EXPERIMENTAL PROCEDURE}

In this paper, the studies of a manufacture process of high temperature piezoelectric material (Curie temperature of $650^{\circ} \mathrm{C}$ ) are presented. Three types of a Sodium Bismuth Titanate (NBT) samples, chemical formula $\mathrm{Na} 0.5 \mathrm{Bi} 4.5 \mathrm{Ti} 4 \mathrm{O} 15$, were manufactured by the screen printing method. Two types of samples were in a form of a detached disk. One type of sample was directly deposited on an alumina substrate. The diameters of the samples were about 0.5 and 1 $\mathrm{cm}$. The thickness was $100 \mu \mathrm{m}$ for detached disks and $40 \mu \mathrm{s}$ for on alumina NBT. Before processing with piezoelectric characterization, the samples were polarized in the silicon oil under an electric field of $100 \mathrm{kV} / \mathrm{cm}$.

The samples were tested regarding their morphological, chemical, resistivity, piezoelectric, dielectric, ferroelectric properties. By studying the evolution of dielectric properties as a function of temperature we were able to determine the optimal conditions for a high temperature sensor manufacture. The first device of an NBT ceramic material on alumina plate 
was tested on its acoustic properties. The measurements of the speed of sound in liquid substances were carried out.

\section{RESULTS AND DISCUSSIONS}

By analyzing the difference in the manufacture process such as grain size of a raw material and sintering conditions, we were able to study samples morphologies. The grain size of powder determines the morphology of ceramics. By increasing sintering time for one type of samples, we were able to process with more dense ceramic structure.

The importance on a chemical composition of a raw NBT material was shown to be the main factor in establishing the material properties. In a case of materials for high temperature applications, we are looking for a ceramic possesses high resistivity. High resistivity means endurance to a voltage and temperature shock thus reliability of sensor operation. From its measurement two types of fabricated samples have a relatively good resistivity.

In order to confirm resistivity values, dielectric properties were measured at room temperature and compared with the state of the art. They are in good agreement with previously reported NBT bulk ceramics [2] for the samples with relatively high resistivity of more than $1 \cdot 10^{13} \mathrm{Ohm} \cdot \mathrm{cm}$.

Piezoelectric charge coefficient has been found to be higher for the samples with a low dielectric loss (high resistivity), approaching the state of the art of $16 \mathrm{pC} / \mathrm{N}$ for bulk NBT [3].

The dielectric properties monitoring as a function of temperature show that the best figure evolution (relative stability of dielectric permittivity and dielectric loss up to $400^{\circ} \mathrm{C}$ ) was obtained for the sample fabricated from a small grain size powder, sintered for 15 minutes. Furthermore, it was a material containing lower quantity of sodium. In an NBT, sodium is substitute bismuth in the A-site of perovskite in Aurivillius structure and is an important element in reducing of the conductivity (this assumption is based on a high conductivity of a Bismuth Titanate ceramic which is a ceramic of the same family not containing sodium [4]). However, in a pure state, sodium is a good electrical conductor [5]. Apparently, for the samples with a low dielectric stability on temperature sodium is in an increased quantity, which explains that loss increases dramatically with a temperature.

Based on material properties evolution as a function of temperature we choose an optimal process on material fabrication. The active NBT material together with screen printed electrodes were deposit on an alumina substrate. The device was joined with a centimetric acoustic cavity filled by water or ethanol. The acoustic signal was generated and acquired by pulser/receiver and oscilloscope. The measurements under room temperature conditions ensure device performance. The speed of sound for water and ethanol were in the good agreement with the state of the art $[6,7]$. In the case of measurement of gas the signal processing as reported in [1] and [8] will be applied.

\section{CONCLUSION}

This study proves the feasibility of acoustic sensor manufacture by screen printing method for high temperature applications. Measurements of dielectric properties as a function of temperature demonstrate the importance of the samples manufacture conditions. Their variation, for on alumina sample, ensures its applicability in the desirable temperature range from 300 to $400{ }^{\circ} \mathrm{C}$. We suggest following the same process of fabrication for subsequent sensors.

The piezoelectric coefficient of samples was in the range of theoretical value for NBT bulk ceramic. Acoustic test for water and ethanol show a high efficiency in the measurement of the speed of sound.

The investigation of sensor properties as a function of temperature for a long-time scale period is the next step in sensor characterization. The experiment with a gas composition measurement are planned to be carried out in the near future.

\section{REFERENCES}

[1] Rosenkrantz, E., Ferrandis, J. Y., Augereau, F., Lambert, T., Fourmentel, D., \& Tiratay, X. (2013). An Innovative Acoustic Sensor for In-Pile Fission Gas Composition Measurements. IEEE Transactions on Nuclear Science, 60(2), 1346-1353.

[2] Wang, C. M., Zhao, L., Liu, Y., Withers, R. L., Zhang, S., \& Wang, Q. (2016). The temperature-dependent piezoelectric and electromechanical properties of cobalt-modified sodium bismuth titanate. Ceramics International, 42(3), 4268-4273.

[3] Subbarao E. A family of ferroelectric bismuth compounds. Journal of Physics and Chemistry of Solids. 1962;23(6):665-676.

[4] Shulman, Holly S., et al. "Microstructure, electrical conductivity, and piezoelectric properties of bismuth titanate." Journal of the American Ceramic Society 79.12 (1996): 3124-3128.

[5] Weast, Robert C., and M. J. Astle. "CRC." Handbook of Chemistry and Physics. Boca Raton, Florida: Chemical Rubber Company Publishing. pp. E 110 (1984).

[6] Del Grosso, V. A., and C. W. Mader. "Speed of sound in pure water." the Journal of the Acoustical Society of America 52.5B (1972): 14421446.

[7] Wilson, Wayne, and David Bradley. "Speed of sound in four primary alcohols as a function of temperature and pressure." The Journal of the Acoustical Society of America 36.2 (1964): 333-337.

[8] Rosenkrantz, E. (2007). Conception et tests d'un capteur ultrasonore dédié à la mesure de la pression et de la composition des gaz de fission dans les crayons combustibles (Doctoral dissertation, Univ. Montpellier 2). 